\title{
The Relationship between Ethics and Aesthetics in Sustainable Architecture of the Baltic Sea Region
}

\author{
Aurelija Daugelaite * and Indre Grazuleviciute-Vileniske \\ Faculty of Civil Engineering and Architecture, Kaunas University of Technology, 44249 Kaunas, Lithuania; \\ idre.grazuleviciute@ktu.lt \\ * Correspondence: aurelija.daugelaite@ktu.edu or aurelijai@gmail.com
}

Citation: Daugelaite, A.;

Grazuleviciute-Vileniske, I. The Relationship between Ethics and Aesthetics in Sustainable Architecture of the Baltic Sea Region. Sustainability 2021, 13, 2259. https://doi.org/ $10.3390 /$ su13042259

Academic Editor: Walter Filho

Received: 30 December 2020

Accepted: 3 February 2021

Published: 19 February 2021

Publisher's Note: MDPI stays neutral with regard to jurisdictional claims in published maps and institutional affiliations.

Copyright: (c) 2021 by the authors. Licensee MDPI, Basel, Switzerland. This article is an open access article distributed under the terms and conditions of the Creative Commons Attribution (CC BY) license (https:// creativecommons.org/licenses/by/ $4.0 /)$.

\begin{abstract}
Architecture, as a mean of art and as a factor that physically shapes the environment, undoubtedly serves as a form of expression of ethical attitudes. It combines ethical values and responsibility for solving environmental problems with aesthetic qualities of the built environment. The holistic approach is gaining ground in the paradigm of sustainability, where architectural concepts such as biophilic, biomimetic, resilient, restorative, and others reinforce the idea of coexistence between humans and nature. In the 21st century, sustainability has become a global phenomenon; therefore, contemporary architecture is expected to reflect the idea of sustainability in its expression. This study explores the relationship between ethics and aesthetics in sustainable architecture in practice. Furthermore, this study attempts to illustrate how the architectural expression of certified sustainable buildings in the Baltic Sea region reflects the trends of sustainability within an ethical paradigm. The research question of this study is as follows: what are the prevailing aesthetic trends and are environmental ethical values expressed in the sustainable architecture of the Baltic Sea region? The study of examples of sustainable architecture was carried out by analyzing the three main databases of certified sustainable buildings-Deutsche Gesellschaft für Nachhaltiges Bauen (DGNB), Leadership in Energy and Environmental Design (LEED) and Building Research Establishment Environmental Assessment Method (BREEAM). The study found eight predominant groups of aesthetic expressions of sustainable buildings and the absence of a distinctive architectural expression that could be considered as sustainability aesthetics. It can be hypothesized that the lack of aesthetic distinctiveness of certified sustainable buildings could be related to the absence of cultural, aesthetically oriented criteria in building sustainability rating systems.
\end{abstract}

Keywords: sustainable architecture; the Baltic Sea region; aesthetics; sustainability aesthetics; building sustainability certification systems; certified sustainable buildings

\section{Introduction}

Sustainability is currently recognized as the most important development trend in societies. It is finding its way into almost all scientific disciplines and fields of practice, including construction and architecture. Although there are numerous definitions of sustainability [1], the so-called Bruntland definition, with its call for the inclusion of intragenerational and intergenerational equity [2], is the most widely accepted. Architecture as a physical shaping factor of our environment, embodying energy and materials as well as expressing our values, undoubtedly serves as a mirror of the sustainability state of societies [3]. Some researchers even claim that contemporary architecture both contributes to sustainability and expresses unsustainability [4-6]. According to Hill [5]), with the rise of modernism, architecture has become one of the most significant commodities and a site of commodity accumulation.

Currently, architecture is associated with increased energy and resource consumption. Based on the full life cycle approach, the global building sector is assumed to be responsible for: half of all extracted materials, half of all energy use, one-third of water 
use, and one-third of waste generation [7]. Grant [4] identifies contemporary architecture's links to overconsumption in relation to competitive status-seeking and with the unsustainable cycle of resource-intensive consumption and labor. The identified links between contemporary architecture and unsustainability together with a general understanding of the environmental impact of architecture and the associated construction industry have led to an ongoing commitment by the architectural profession to sustainability or the so-called "green imperative for sustainability in architecture" [8,9]. Since the World Congress of the Union of International Architects in 1993, the concept of sustainability has been increasingly applied by the architectural profession, including world-renowned architects such as Richard Rogers. In 1993, the Congress promulgated the declaration, which emphasized that sustainable design should become a normal practice [8].

Furthermore, contemporary legal frameworks in numerous countries and supranational entities, such as the European Union (EU), and even the global development paradigm dictate that some aspects of architectural sustainability are enforced by law. Institutions that make the achievement of sustainability in the fields of architecture and construction becomes "inevitable", as Jauslin [10] states. Take, for example, the global United Nations Sustainable Development Goals-SDGs [11]. At least seven of them relate directly to the sustainability of living environments and buildings, in particular: SDG 3-Good health and well-being; SDG 6-Clean water and sanitation; SDG 7-Affordable and clean energy; SDG 11-Sustainable cities and communities; SDG 12-Responsive consumption and production; SDG 13-Climate action; SDG 15-Life on land.

Sustainability concerns of living environments reflect the need for solutions in regional and urban planning, and architectural design. Although the SDGs generally reflect ethical values, SDG 11 holds aesthetic potential. SDG 11 focuses on making cities and human settlements inclusive, safe, resilient and sustainable, where sustainability aesthetics can be an important quality criterion [12,13]. The European Commission is on track to develop a common framework for assessing the sustainability performance of buildings to integrate the building sector into the EU's evolving circular economy [7]. Increasing energy performance requirements for buildings are being enforced by law in EU member states [14]. Moreover, the general perception of architecture in EU member states is evolving in line with the sustainability paradigm. For example, the current Lithuanian Law of architecture defines the principle of sustainability as one of the quality criterion of architecture [15].

The achievement of many of the Sustainable Development Goals and objectives is quantifiable, which may give the impression that it is primarily a technological challenge. However, Fox [8] emphasizes sustainable development as an ethical category. Moldovanova [16] also highlights that sustainability includes an ethical dimension. However, in her opinion, the concept of sustainability ethics has received less attention in the literature on sustainable development issues. Moreover, in the field of environmental ethics, of which the sustainability concept is an integral part, there is a wide range of approaches-from anthropocentric to eco-centric ones [3]. The concept of sustainability is constantly evolving to include restorative and regenerative concepts [17].

Considering the aforementioned shift of the sustainability paradigm, the literature on sustainable design, as well as the number of projects and realizations labeled as "green", "sustainable" and "ecological" is increasingly growing. Sustainability certification schemes such as BREEAM and LEED have accelerated this process in recent decades. However, some architectural critics and researchers [18] note that sustainability certification schemes do not encourage the development of some aspects of sustainability, such as architectural aesthetics, which often remains ignored. This makes the aesthetic expression of sustainable buildings a relevant research object.

Furthermore, regional peculiarities are undoubtedly relevant to sustainable architecture, including climatic and material aspects, aesthetic expression, and the links with the context of buildings. Some authors even identify a sense of place, or the so-called spirit of the place, as an imperative for environmental ethics [19] and the aesthetics of sustainable architecture. Considering the relevance of regionality, this research focuses on the ethics 
and aesthetics of sustainable architecture of the Baltic Sea region. In this research, the Baltic Sea region is considered as a territory that includes countries that have coastlines along the Baltic Sea: Denmark, Estonia, Latvia, Finland, Germany, Lithuania, Poland, Russia, Norway, and Sweden. The research question of this study was formulated as follows: What are the prevailing aesthetic trends and are the environmental ethical values expressed in the sustainable architecture of the Baltic Sea region?

\section{Materials and Methods}

To answer the research question, the methodology, including a literature review (synthesis and analysis) and the case studies of examples (comparison and classification) was formulated. The literature review was used for the two main objectives: to define the concepts of sustainable architecture and to clarify the notion of sustainability aesthetics. Literature sources were searched in the main scientific databases-Scopus and Web of Science, using the keywords "sustainable architecture" and "sustainability aesthetics". An additional search was conducted using general search engines. This additional search uncovered valuable articles and monographs in the professional press that were not included in scientific databases.

The definition of sustainable architecture was formulated based on the general literature on sustainability [2] and research in the fields of architecture [20,21], design [22], and landscape [23]. The definition of the notion of sustainability aesthetics was based on the ideas of Kagan [6]. The existing classifications of aesthetic expression of sustainable architecture [24-26] and the messages potentially embodied in sustainable buildings [5,24,26] were also analyzed. The features of sustainability aesthetics identified by Kagan [6], such as complexity and complementarity of opposites, serve as the analytical approach for the selected examples of certified sustainable buildings.

The analysis of the examples focused on the territory of the Baltic Sea region, which includes the following countries: Denmark, Estonia, Latvia, Finland, Germany, Lithuania, Poland, Russia, Norway, and Sweden. The sustainable building certification schemes used internationally in this region are Deutsche Gesellschaft für Nachhaltiges Bauen (DGNB), Leadership in Energy and Environmental Design (LEED), and Building Research Establishment Environmental Assessment Method (BREEAM). The databases of these schemes were selected as a source of examples of certified sustainable buildings for the analysis. The time-frame for the analysis was defined as 2016-2020 (except in the case of BREEAM, where some earlier examples were included). The aesthetic expressions of a total of 112 buildings, mainly for public and commercial use, were analyzed.

Based on the aesthetic similarities of the collected buildings, forty distinctive sustainable buildings were selected for further analysis and divided into eight categories representing different prevailing trends. The selected examples were discussed from the perspective of sustainability aesthetics. Finally, the conclusions were formulated.

\section{Results}

\subsection{Defining the Sustainable Architecture}

The definition of sustainable architecture or sustainable architectural design is quite complex. According to Marchand et al. [22], sustainable design "involves reconsidering the way objects are thought about, developed, produced, distributed, used, reused, recycled, and disposed". They stated that sustainable design objects have a broader social-cultural impact and promote new ways of living. Musacchio [23] identified six dimensions of environmental sustainability: environment, aesthetics, ethics, equity, experience, and economy. These two contributions from the fields of architectural design and landscape management show that sustainability is not limited to resource consumption or energy conservation. It can be considered that sustainable architecture is entirely based on the principles of sustainability. These principles include the pursuit of material and immaterial well-being, equity for present and future generations, justice within and between societies, protection and promotion of cultural and biological diversity, precaution in decision-making, and 
recognition of the interdependence of phenomena [2]. Architectural sustainability is programmed at the initial project development stage-it begins with an idea and continues throughout the building's life cycle: design, site preparation, construction, demolition or renovation. A sustainable building is not only durable, long-lasting, and environmentally friendly, but also contextual, aesthetic, and psychologically acceptable. Sustainable architecture promotes the sustainable development of the environment and society, including the conservation of resources and energy, as well as social cohesion, to contribute to the improvement of the quality of life in a broader sense [21].

According to Heymann [18], sustainability certification does not stimulate the evolution of the aesthetic expression of sustainable buildings towards a more coherent representation of the ethical values of sustainability. The definitions of sustainable architecture presented in this research allow us to conclude that, as there is a "green imperative for sustainability in architecture" [8,9], an aesthetic imperative should exist in sustainable architecture to the same extent. Sustainable architecture not only contributes to environmental, social, and economic sustainability, but also has a high aesthetic quality and recognizability. This encouraged analysis of the links between ethics and aesthetics in sustainable architecture both from a theoretical point of view and the manifestations of these links in actual sustainable buildings.

\subsection{Aesthetics of Sustainable Architecture}

The term "aesthetics" was coined in the 18th century by the German philosopher Alexander Baumgarten, who defined aesthetics as the science of sensory perception [27]. Hill [5] states that the contemporary debate on aesthetics, including architectural aesthetics, can be characterized by the separation between the perceiving subject and the world of objects around them. According to him, this clear separation emerged in the dawn of modernity and currently the term "aesthetics" can refer to both the subjective experience and the properties of the object.

Marchand et al. [22] also agree that the terms "aesthetics" or "aesthetic qualities" are usually associated with which object is perceived by the senses. In relation to aesthetic experience, the term "aesthetics" refers to some aspects of the cognitive response. In the first case, it is focused on the properties of a particular object; in the second, it is concerned with the experience of those properties, which may also be influenced by assumptions or preconceptions of the subject that is not directly related to the object. In contemporary aesthetic theories, however, attempts can be traced to seek the relationship between subject and object in aesthetic experience. For example, British anthropologist, sociologist, linguist, and expert in many other fields G. Bateson, defined aesthetics as a response to connecting patterns. He defined the percipient's aesthetic priority as the mind's ability to recognize features similar to those of another system it has encountered. According to G. Bateson, a characteristic questions of aesthetics would be: "How are you related to this object or entity? What structures connect you?" [6]. Researchers emphasize that the phenomenon of sustainable development still lacks a new, recognizable aesthetic language [24]. Few precise definitions of sustainability aesthetics can be found in the academic literature. In many cases, descriptions of the artistic expression of objects, trends or classifications of sustainable architecture are presented without specifically defining what the aesthetics of sustainability is. A specific description of the aesthetics of sustainability was provided by Kagan [6]. He derives this definition from G. Bateson's concept of aesthetics as a response to connecting patterns and argues that this aesthetics focuses on relationships and processes and are based on a sensitive response to connecting structures at many levels. Following G. Bateson, Kagan [6] suggests focusing not only on the immediately visible differences between the elements of the lifeworld, but to looking at the metastructure that binds the lifeworld together.

In this way, the aesthetics of sustainability is encouraged to emphasize the complementarity of opposites. This new language of sustainability aesthetics should not be afraid of complexity and should be based on complex and dynamic networks of life in the envi- 
ronment and the social, political, and economic complexities of modern societies, open to the creative forces of chaos and unexpected outcomes.

A. Marchand et al. [22] note that the aesthetics of sustainability stimulates not only changes in the aesthetic quality of the objects around us, but also changes in the meanings associated with the aesthetic properties of our environment, including objects. Aesthetics becomes an important cultural aspect in the definition of sustainable architecture (Figure 1).

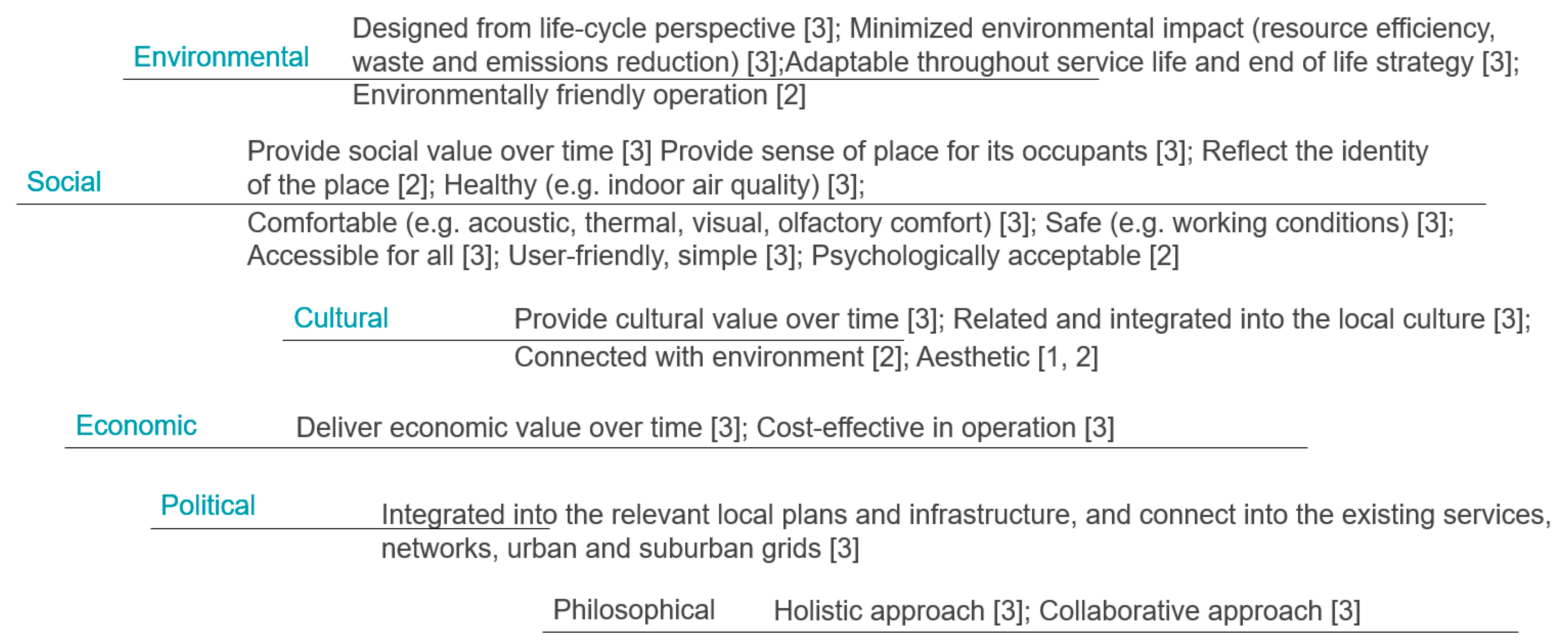

Figure 1. What properties define sustainable architecture in line with sustainability dimensions? (Image by authors based on 1-[20], 2013; 2-[28]; 3-[29]).

The debate about what is sustainable architecture is ongoing, and the aesthetics of sustainable architecture is not only associated with green roofs and adobe or straw buildings, but also with high-tech systems, such as solar panels, building automation systems, and double facades [30]. Guy and Farmer [25] emphasized that sustainable architecture is a "contested concept". Researching the expression and development of sustainable architecture, they observed the characteristic "technocentrism" that disregards the sensitivity to place and culture. Guy and Farmer [25] distinguished eco-technical (future-oriented architecture), eco-centric (autonomous, recycled architecture in harmony with the natural environment), eco-aesthetic (iconic buildings), eco-cultural (architecture sensitive to the cultural context and using local traditions), eco-medical (architecture of natural materials focused on health, quality of life and well-being), and eco-social (community-based architecture) expressions of sustainable architecture. Recognizable architectural aesthetics undoubtedly characterize each of these trends.

Sauerbruch and Hutton [26] distinguish several approaches to sustainable architecture and its aesthetics: (i) a quantitative approach that focuses primarily on energy and cost reduction, and on listing sustainability criteria and certification. In this case, the question of the aesthetics of the building is left aside and focused mainly on quantifiable, technical aspects-the building is not treated as an architectural object, but as a temporary stage of a larger life cycle, a certain "storage" of building materials to be recycled or reused in later stages of the cycle; (ii) the desire to recreate and interpret the aesthetics of the past, of historical architecture, which is considered inherently sustainable; (iii) the pursuit of the most ecologically efficient forms, "form follows ecological function". The so-called "solar architecture" or "solar aesthetics" [31], "passive house" or "passive design"[32], where the form of the building aims to adapt to the environment and use renewable energy sources as efficiently as possible, can also be attributed to this concept. Biomimetic design [26,33], in which objects are designed with biomorphic forms, can also be classified in this trend. In the latter case, the basic idea is a building that looks and functions like a living organism, but, as M. Sauerbruch and L. Hutton [26] note, the synergy with nature often remains only as an intention, and the result can be called biomorphic formalism. 
There is considerable discussion in the literature about what values are expressed through the aesthetics of sustainability [5,24,26]. According to Hill [5], architecture should express more than the social status of the owner or the talent of the architect. Meyer [34] observes that the aesthetics of sustainability should bear witness and highlight aspects of the current environmental crisis, the architecture of buildings should reflect the public interest in ecology and environmental concerns inherent in modern culture [26]. In addition to revealing the ecological crisis through architectural aesthetics, there is another trend-the creation of highly aesthetically appealing ecological products and environments [24,26]. In this case, architecture can literally become an advertisement for alternative lifestyles, demonstrating that a reduction in consumption does not necessarily mean a reduction in quality [26].

\subsection{Environmental Ethics and Aesthetics of Certified Sustainable Buildings in the Baltic Sea Region}

Environmental ethics is a branch of environmental philosophy [35]. It is "focused on the complex human-nature relationship that manifest in environmental problems such as the loss of species and wildlands; air, land, and water pollution; overpopulation; and resource scarcity" [29]. Environmental ethics emerged in early 1970s as a result of the search for a more respectful approach to the environment and its components-living and non-living organisms.

Ongoing changes in the ethical dimension of architecture reveal new attitudes about how we behave in our environment. Currently, there are a variety of concepts that are slowly expanding the anthropocentric concept of sustainable development and proposing future approaches to holistic architecture. Scientific studies (e.g., [20,36,37]) show the ongoing shifts in the sustainability paradigm towards systemic, dynamic, organic, holistic, and non-linear approaches. Emerging concepts of resilient, restorative, regenerative architecture, and others highlight the aspiration to restore the lost connection with the natural world, as well as to develop coexistence between humans and nature in the urban environments of the future.

These trends are reflected in certification schemes of sustainable buildings. For example, the Living Building Challenge (LBC) certification system, seen as an extension of LEED, has introduced criteria of equity and beauty into the evaluation of sustainable architecture. Beauty is defined there as "celebrating design that uplifts the human spirit". Although, it is almost impossible to define beauty, biophilic design is highlighted as a mean to createg beautiful buildings: "The key to creating beautiful buildings is to embrace a biophilic design process that emphasizes that people and nature are connected and the connection to place, climate, culture and community is crucial to creating a beautiful building" [38]. However, this certification system is rarely used in the Baltic Sea region. The certification systems that are applied internationally in this region are DGNB, LEED, and BREEAM (Table 1).

The question arises as to what are the prevailing aesthetic trends and are environmental ethical values expressed in the sustainable architecture of the Baltic Sea region. In order to obtain answers, further research was conducted. Sustainable buildings were analyzed by searching three main databases of certified sustainable buildings-DGNB, LEED and BREEAM. The search criteria included certified new construction buildings in countries of the Baltic Sea region in 2016-2020 (except in the case of BREEAM, where some earlier examples were included). The main difficulty in the search was the lack of visual information on the projects, especially in the LEED and BREEAM databases; this required additional research on each project to find visual references and assess the aesthetic expression. Consequently, the search became rather selective. However, the aim remained to collect as many examples as possible.

The number of buildings analyzed reached 112. The selection process included: the BREEAM certification database [40] has numerous certification cases in the all countries analyzed; however, visual information is not included in the database itself. Therefore, 
14 buildings (new construction) - 5 from Norway, 1 from Sweden, 2 from Lithuania, 2 from Russia, 4 from Poland-were selected for the further investigation.

Table 1. Certification systems that are the most usually applied in the Baltic Sea region, [26,30,39-42]).

\begin{tabular}{|c|c|c|c|c|}
\hline No. & Certification System & Origins & Focused on & $\begin{array}{l}\text { Certificate Rating } \\
\text { (Highest-Lowest) }\end{array}$ \\
\hline 1 & $\begin{array}{c}\text { BREEAM } \\
\text { (Building Research } \\
\text { Establishment Environmental } \\
\text { Assessment Method) }\end{array}$ & $\begin{array}{l}\text { United Kingdom } \\
1990\end{array}$ & $\begin{array}{l}\text { energy, health and wellness, innovation, } \\
\text { use of the soil, materials, management, } \\
\text { pollution, land use and ecology, } \\
\text { transport and waste }\end{array}$ & $\begin{array}{l}\text { Outstanding } \\
\text { Excellent } \\
\text { Very good } \\
\text { Good } \\
\text { Pass } \\
\text { Acceptable }\end{array}$ \\
\hline 2 & $\begin{array}{c}\text { LEED } \\
\text { (Leadership in Energy and } \\
\text { Environmental Design) }\end{array}$ & $\begin{array}{l}\text { USA } \\
1998\end{array}$ & $\begin{array}{c}\text { location and transport, sustainable sites, } \\
\text { efficiency of water use, energy and } \\
\text { atmosphere, materials and resources, } \\
\text { internal environmental quality, } \\
\text { innovation and processes, regional } \\
\text { priority credits }\end{array}$ & $\begin{array}{l}\text { Platinum } \\
\text { Gold } \\
\text { Silver }\end{array}$ \\
\hline 3 & $\begin{array}{c}\text { DGNB } \\
\text { (Deutsche Gesellschaft für } \\
\text { Nachhaltiges Bauen) }\end{array}$ & $\begin{array}{l}\text { Germany } \\
2007\end{array}$ & $\begin{array}{l}\text { holistic approach, life cycle, } \\
\text { sociocultural and functional, } \\
\text { environmental, economic, site, technical } \\
\text { and process quality assessment }\end{array}$ & $\begin{array}{l}\text { Platinum } \\
\text { Gold } \\
\text { Silver } \\
\text { Bronze }\end{array}$ \\
\hline
\end{tabular}

The LEED certification database [43] included examples in all countries; however, the lack of visual information limited the study. A total of 35 buildings were selected for further study: 1 in Norway, 3 in Sweden, 3 in Finland, 1 in Russia, 2 in Estonia, 3 in Latvia, 4 in Lithuania, 13 in Poland, 4 in Germany, and 1 in Denmark.

In the DGNB certification database [44], examples in Norway, Sweden, Finland, Russia, Estonia, Latvia, and Lithuania were not found; due to the large number of certified buildings in Germany, buildings certified in Silver were removed from the search. A total of 4 buildings in Poland, 1 in Denmark, and 336 in Germany were distinguished and the search was narrowed down to 63 buildings, selecting the most characteristic and representative examples.

It was not possible to classify those selected certified sustainable buildings according to the existing aesthetic expression classifications (for example, classifications of Guy and Farmer [25] or Sauerbruch and Hutton [26]). In this case, the classification according to the existing systems was not meaningful, as the majority of the analyzed buildings could be assigned to quantitative [26] or eco-technical [25] approaches or even had no explicit sustainability-related aesthetics and could be assigned to general architectural styles such as functionalism, minimalism or international style.

The group of buildings, distinguished by wooden architecture and smaller scale clearly stands out in the context of the other buildings analyzed. It was also possible to distinguish a group with more expressive curvilinear shapes of public and commercial buildings. From this initial analysis, the need arose to introduce an additional classification of the aesthetic trends of the certified sustainable buildings of the Baltic Sea region in order to capture the more subtle diversity of architectural expression within the stylistic current that can be broadly described as minimalism. In developing this classification, consideration was given to the overall aesthetic appearance of the building, its volume and form, materials that determine aesthetic expression, and adherence to commonly known architectural styles. Consequently, eight groups of aesthetic expression of certified sustainable buildings of the Baltic Sea region were distinguished, which are presented and described below (Figures 2-9). Kagan's [6] definition of sustainability aesthetics was used to further analyze the grouped architectural examples. 


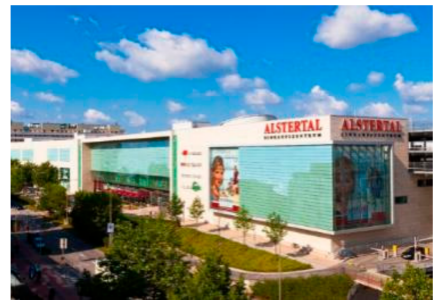

1

Alstertal Einkaufszentrum, Hamburg Germany |2020 |DGNB|Platinum

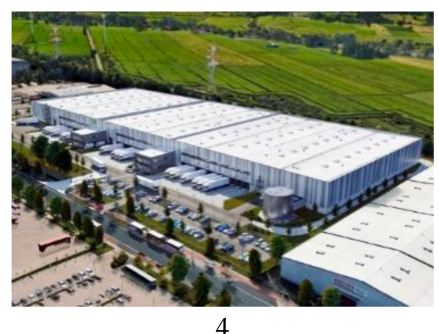

Port Bremen West Logistics Centre Germany | 2020 |DGNB | Gold

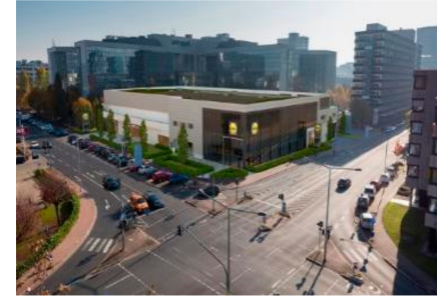

2

LIDL-Metropolfiliale, Frankfurt

Germany |2019|DGNB|Gold

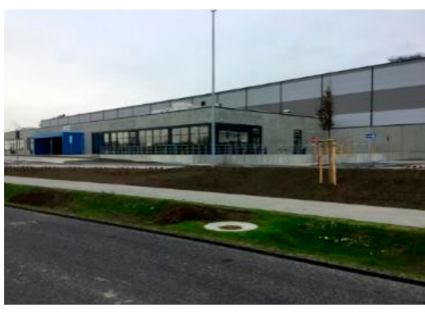

5

May Sortation Center Kiekebusch Germany | 2020 | DGNB | Platinum

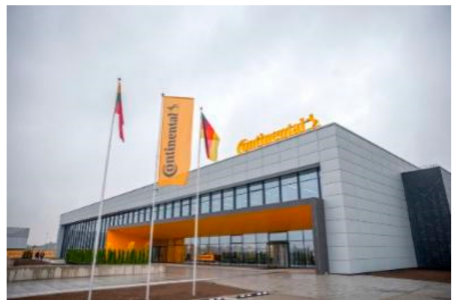

3

Continental Automotive

Lithuania | 2020 | LEED | Gold

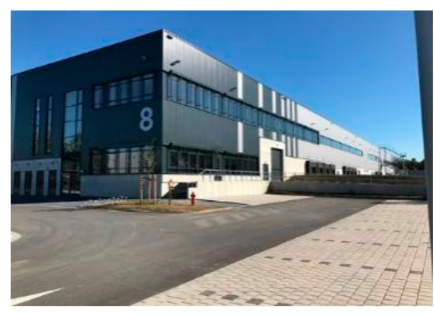

6

GI0276-EXETER Unna II Germany | 2019|DGNB | Gold

Figure 2. First group-industrial aesthetics. It contains buildings with large and mostly monotonous volumes, detached from their contexts, constructed of artificial, synthetic materials, and having low aesthetic values (image source: $[43,44]$ ).

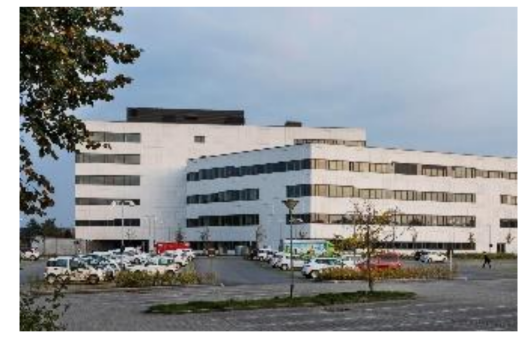

7

Sundhedshuset, Vejle Denmark | 2016 | LEED | Gold

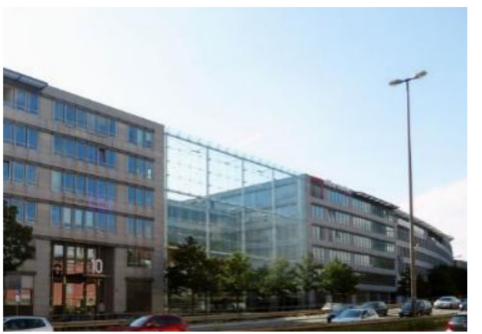

10

Landshuter Allee 8-10, München Germany | 2019|DGNB | Gold

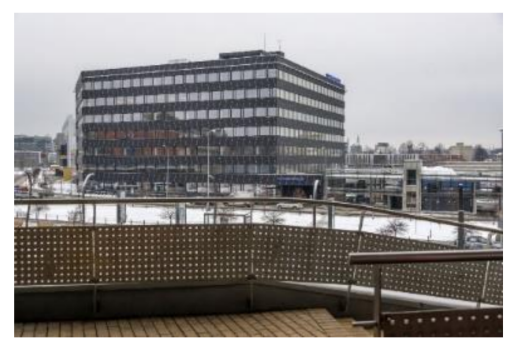

8

Business Centre Penta Lithuania | 2018 | LEED | Gold

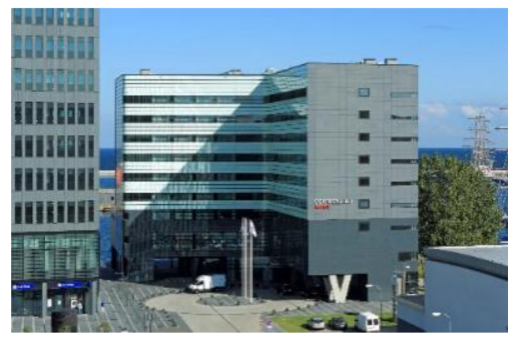

11

Gdynia Waterfront-Courtyard Marriott | Poland | 2016 | LEED | Gold

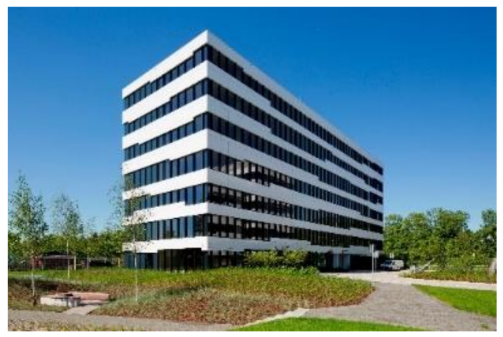

9

Business Garden Warsaw Building 7| Poland | 2017 | LEED | Platinum

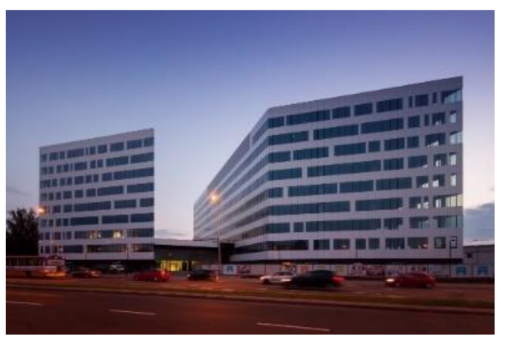

12

Kapelanka 42 B, Krakow Poland | 2018 | LEED | Gold

Figure 3. Second group-large volume minimalism. It contains buildings with large volumes, in which the aesthetic expression is focused on design of the facades (image source: $[43,44])$. 


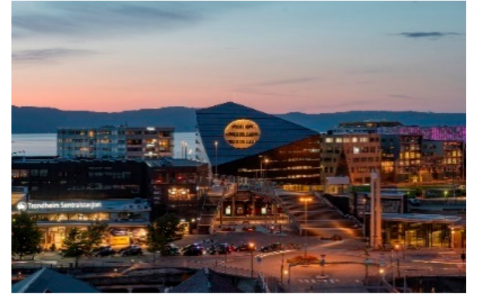

13

Powerhouse Brattørkaia | Norway |2019|BREEAM | outstanding

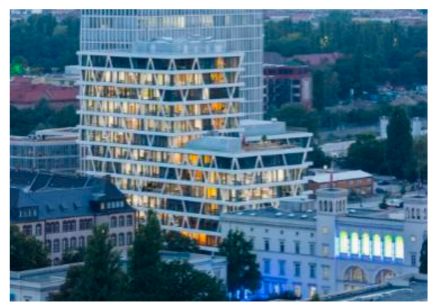

16 50 Hertz

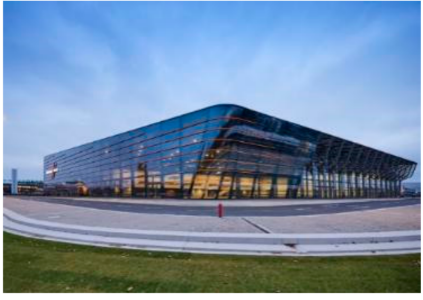

14

Neubau Halle 3C, Nürnberg Germany |2019|DGNB | Platinum

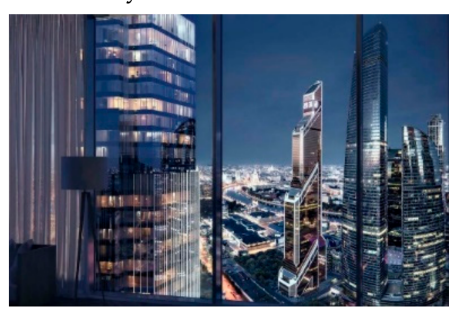

17

Neva Towers T2

Moscow | Russia | 2019 |LEED | Gold

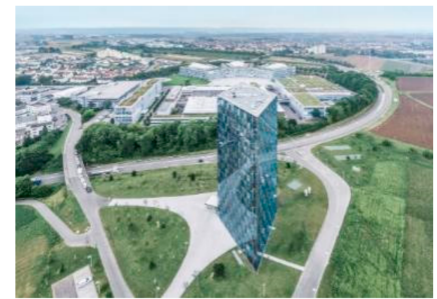

15

AutomationCenter | Germany | 2017 |DGNB | Platinum

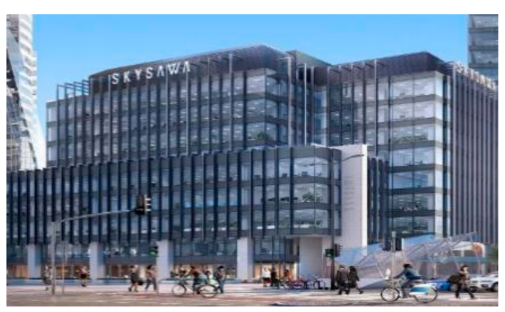

18

SKYSAWA Building A

Poland | 2016 | BREEAM | outstanding Award Diamond I LEED I Gold

Figure 4. Third group—glass aesthetics. It contains buildings in which glass structures dominate. Usually they have more vivid compositions and aesthetic solutions (image source: [43-45]).

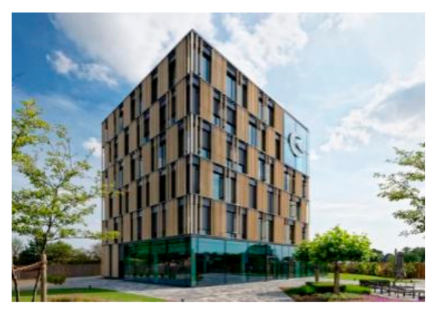

19

Bürogebäude in Hybridbauweiseshopware AG Germany | 2020 IDGNB | Gold

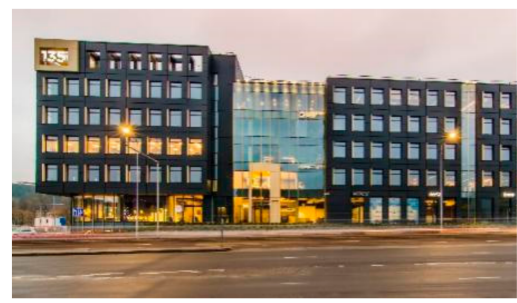

22

Business centre 135

Lithuania | 2016 | BREEAM| outstanding

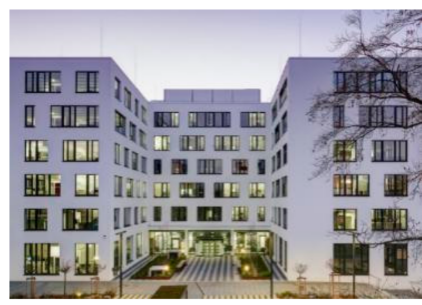

20

FrankenCampus 146, Nürnberg Germany | 2020 |DGNB | Gold

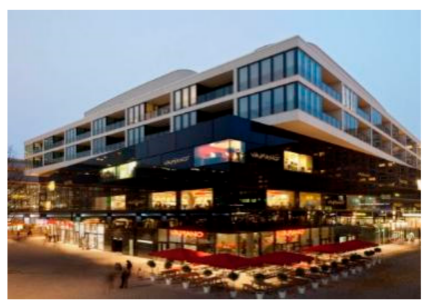

23

ALEA 101 Geschäftshaus Germany | 2016|DGNB | Platinum

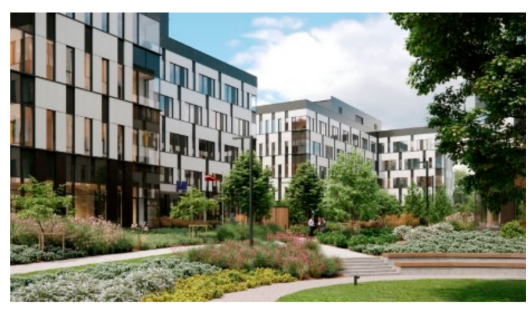

21

Business Garden Riga Building C Latvia 2020 | LEED | Platinum

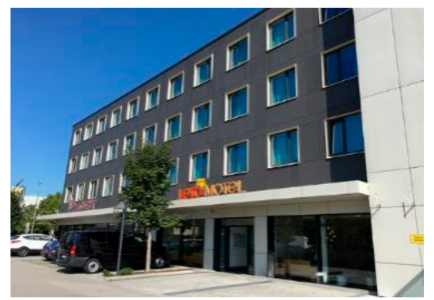

24

Motel München

Germany | 2019|DGNB | Gold

Figure 5. Fourth group-modernist-functionalist aesthetics. It contains buildings with smaller volumes; their aesthetic solutions are often more dynamic and include more intense rhythms and compositions of facades (image source: [40,43,44]). 


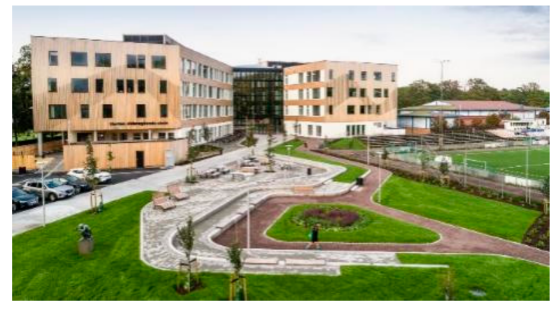

25

Ny Horten videregående skole Norway | 2019|BREEAM | outstanding

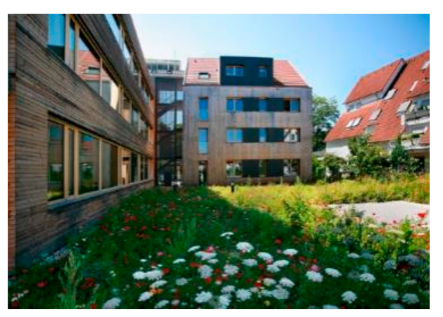

28

Eisbärhaus Bauteile A+B Germany | 2020 |DGNB | Platinum

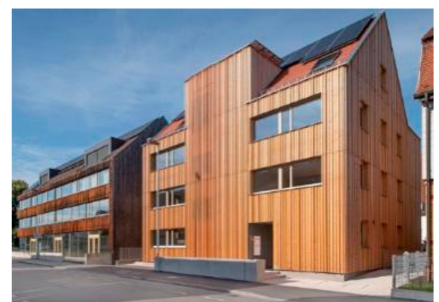

26

Neubau Eisbärhaus Bauteil C Germany |2020 |DGNB | Platinum

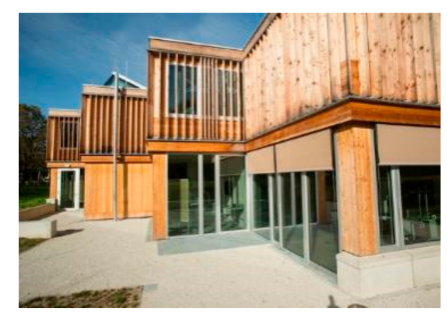

29

Akademie der GIZ am Campus Kottenforst Germany | 2019|DGNB | Gold

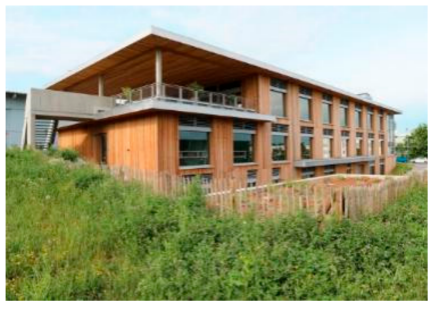

27

Zedler-Institut Fahrradwelt Germany | 2020 |DGNB | Platinum | Award Climate Positive

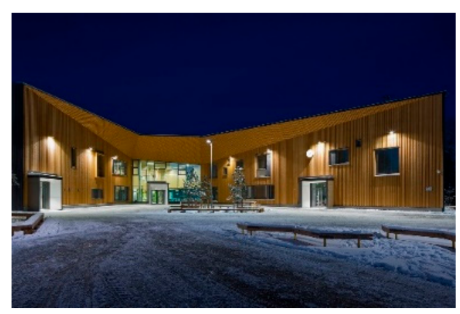

30

Hiukkavaaran monitoimitalo Finland | 2017 | LEED | Gold

Figure 6. Fifth group—smaller scale, dynamics and natural materials. Buildings with smaller volumes are found, and the ecological idea is expressed through use of natural, recyclable materials (image source: $[40,43,44]$ ).

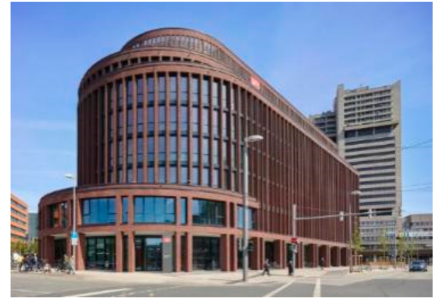

31

Neubau Bürohaus Lister Dreieck Germany | 2020 |DGNB | Platinum

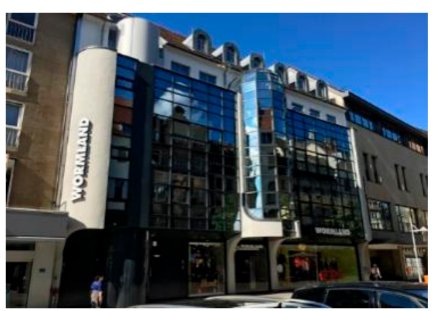

32

Einzelhandelsobjekt Nürnberg Breite Gasse Germany | 2019|DGNB | Gold

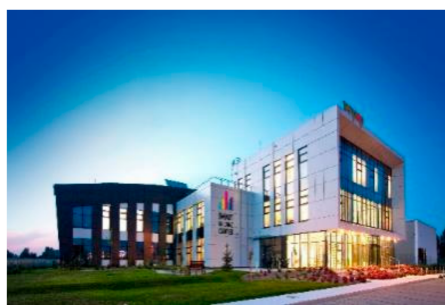

33

Smart Building Center-W.P.I.P Poland | 2016 | LEED | Platinum

Figure 7. Sixth group—dynamic aesthetics, influenced by postmodernism. This group contains buildings with dynamic aesthetic expressions that can be stylistically associated with the trends of postmodernism (image source: $[43,44]$ ). 


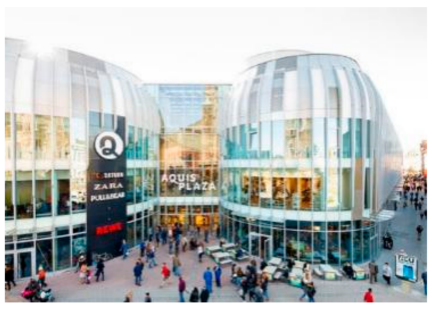

34

Aquis Plaza Aachen Germany | 2018|DGNB | Gold

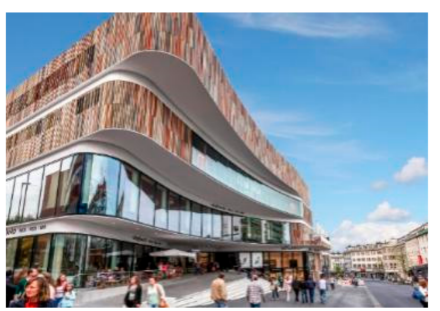

37

Minto, Mönchengladbach Germany | 2016|DGNB | Platinum

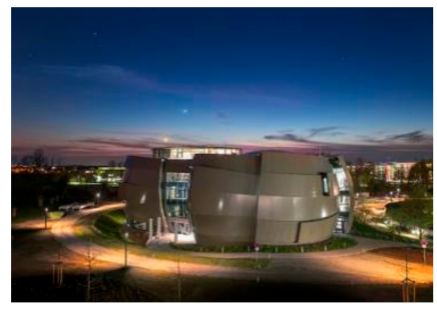

35

ESO Supernova

Germany | 2018 | DGNB | Gold

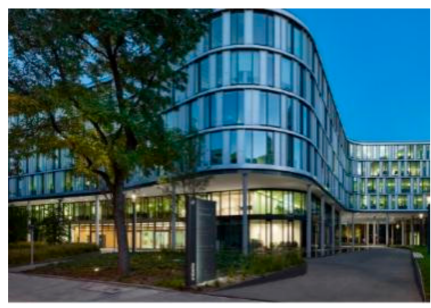

38

Arabeska, München Germany |2016|DGNB| Platinum

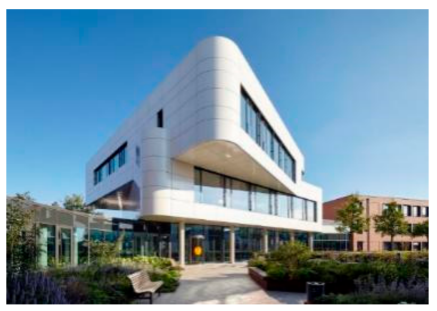

36

Erweiterung ServiceZentrum Volksbank Mittelhessen

Germany | 2016 | DGNB | Gold

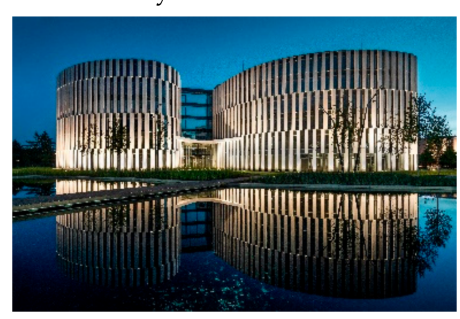

39

Business Garden, Warsaw Building 5

Poland | 2017 | LEED | Platinum

Figure 8. Buildings with clearly expressed curvilinear forms, with characteristic facades. Some of the buildings are close to the so-called "blobism" forms (image source: $[43,44]$ ).

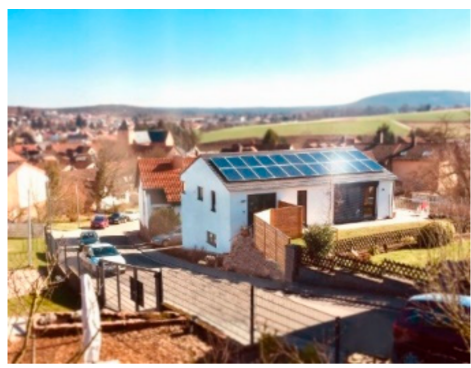

40

Holthaus, Enkenbach-Alsenborn

Germany | 2018 |LEED | Platinum

Figure 9. Eighth group—rural aesthetics. It contains buildings with small volumes, usually scaled to a single-family house (image source: [43]).

The first group analyzed-industrial aesthetics-reflects a technocentric, functionalist approach. This group can even be classified under the regulative aesthetic approach according to Di Carlo [24]. This is a normative, quantitative approach that focuses primarily on energy and cost reduction. The main aesthetic features of this group are a lack of sensitivity to place and culture, and a lack of engagement with the environment mixed with functionalist architectural expression. This group does not currently exhibit sustainability aesthetics potential. However, even utilitarian buildings can achieve sustainability symbolism and ecological functions through means such as green or brown roofs or vegetated facades.

The second group-large volume minimalism-and the fourth group - modernistfunctionalist aesthetics-are quite similar groups, where the main difference is scale. Both groups also reflect a technocentric approach that is evaluated in terms of quantifiable sustainability assessment. Attempts to find aesthetic solutions for architectural compositions are usually limited to a moderate, minimalist, and often rigid facade aesthetics, which is usually based function of the building. Sustainability aesthetics of these architectural 
trends can potentially be developed by reconceptualizing ecological, biological, and cultural relationships through the inclusion of natural features and spaces that can enhance social cohesion and viability, through the use of natural materials, and through engagement with environmental forces such as wind, water, and sunlight.

The third group - glass aesthetics—is mainly based on a technocentric approach. The dominance of glass structures and complex volumetric compositions determines the aesthetic language, which reflects the technology and progress of the 21st century. However, the relation with nature is not expressed, despite the transparency properties of glass. This group's aesthetic sustainability potential can be strengthened in this group through the creation of and an improvement of relations with nature and society.

The fifth group - buildings characterized by smaller scale, dynamism, and the use of natural materials - emphasizes the the pursuit of ecological aesthetics. Building forms remain minimalist and sometimes formal. The selection of natural materials and landscape solutions around the building creates a sense of relational architectural expression that is closer to nature and shows an attempt to demonstrate an ecological approach. However, the materials used do not vary - the facades are usually finished with wood cladding. Although technocentrism plays an important role, efforts to reflect ecological ideas through the aesthetics of the building are evident. In general, sustainable aesthetic features such as relation-centered approaches, attention to complexity, and complementarity of antagonisms are found in this group. The potential of sustainability aesthetics is high when these features are emphasized.

The sixth group - architecture with dynamic aesthetics reflecting postmodern stylesshows an aesthetics that seems more connected to the ideas of the recent past and does not reflect the ideas of the sustainable future. Tehcnocentrism remains as the main focus point in terms of sustainability in this group of buildings. However, aesthetic sustainability potential can be seen here in the attention to complexity that is naturally inherent in the architectural language of postmodernism, full of stylistic and cultural references.

The seventh group - architecture, with dominant aesthetic compositional features of curvilinear forms - can be associated with the idea of organic forms that, but these are not clearly expressed. Architectural composition here is more complex, and architecture expresses new technological possibilities; however, ecological aesthetics as organic or biomimetic architectural approaches are weakly expressed. The potential of sustainability aesthetics of this group is high if the relation-centered approach, such as relationships with the landscape, the cityscape, attention to complexity, and complementarity of antagonisms is strengthened.

The eighth group—rural aesthetics—reflects the orientation towards aesthetics of the past indicated by Sauerbruch and Hutton [26]. Relationships to local traditions and culture play an important role here. Aesthetic expression is regionally dependent, and the main feature of sustainability aesthetics is the complementarity of antagonisms from the point of view that sometimes new architecture acquires traditional aesthetic expressions that are accompanied by added ecological value. A relational approach to landscape, communities, and the spirit of the place can also play important role in further development of this style.

\section{Discussion and Conclusions}

Architecture is both a form of art and a factor that physically shapes our environment. It influences virtually all dimensions of sustainability. At present, the field of architecture is confronted with major contradictions. On the one hand, it is associated with the increasing consumption of energy and resources; on the other hand, it is responsible for the implementation of a sustainable and ecological design paradigm. Nevertheless, the concept of sustainability as an ethical paradigm has evolved from its original definition as a human-centered approach to a holistic approach of human-environment co-creation.

This study examines how the architectural expressions of 112 recent buildings, which are certified as sustainable and located in the Baltic Sea region, reflect ethical trends in sustainability. This research allowed us to identify both the challenge of technocentrism 
in sustainable architecture and the lack of distinct sustainability aesthetics. At the same time, it showed the importance of the regionality of sustainability aesthetics and its existing potential even in functionalist and minimalist architectural buildings.

At first glance, it can be observed that the analyzed buildings of the Baltic Sea region, certified according to LEED, BREEAM or DGNB, lack distinct architectural features that could be called sustainability aesthetics, as they are focused on normative and technical aspects of energy and cost reduction [26]. This may be a consequence of the fact that aesthetic requirements are not included in the criteria of most sustainable building certification schemes. It can be concluded that the technocentrism problem of sustainable architecture identified by Guy and Farmer [25] is present in the analyzed context. It is also possible to agree with the opinion expressed by Di Carlo [24] regarding the lack of aesthetic language of sustainable architecture. One of the possible solutions to this problem could be the requirement to apply the holistic approach in certification schemes for sustainable buildings A good example of this solution is the Living Building Challenge certification scheme, which integrates not only environmental, economic, and social sustainability criteria, but also cultural criteria, including aesthetic quality.

A unified approach to assessing and reporting the sustainability performance of buildings is currently being developed at European Commission [7]. It consists of three themes - resource and environmental performance; health and comfort; and cost, value and risk. It is evident that cultural factors, including architectural aesthetics, are barely present in this framework. Although architectural aesthetics can alternatively be considered as an area outside of sustainability debate and assessment, it cannot be denied that the primary focus of attention, effort, and resources to achieve the environmental and economic goals of sustainability assessment programmes influences architectural aesthetic outcomes. This calls for further and more detailed investigation of the interrelationships between the criteria systems applied in different sustainability certification schemes for buildings and the aesthetic expressions of the certified buildings.

The case studies conducted allowed us to classify sustainable buildings of the Baltic Sea region into eight groups according to their aesthetical expressions: (1) industrial aesthetics, (2) large volume minimalism, (3) glass aesthetics (4) modernist-functionalist aesthetics, (5) smaller scale, dynamics, and natural materials, (6) dynamic aesthetics that reflects postmodernism, (7) curvilinear forms, and (8) rural aesthetics. This classification allowed us to identify connections and potential of sustainability aesthetics. For example, groups of functionalist and minimalist buildings and glass structures can still create meaningful and fruitful ecological, biological, and cultural relationships by incorporating natural features and spaces that can strengthen social cohesion and viability through the use of natural materials and by engaging with environmental forces such as wind, water, and sunlight. The complexity and presence of multiple and sometimes contradictory cultural references in the architectural language of postmodernism, as seen in some examples, has the potential to be integrated into the development of sustainability aesthetics. The long tradition of timber construction in the Baltic Sea region as well as a relational approach to landscape, communities, and the spirit of the place in the rural architecture can be seen as promising developments in sustainability aesthetics.

This research confirmed the importance of regionality and cultural context in the architectural expression of sustainable buildings. The fact that the aesthetic expression of the analyzed and certified as sustainable buildings of the Baltic Sea region does not conform to the existing typologies of sustainable architecture styles. It is more oriented towards minimalism, which can be partly explained by Baltic-Nordic modernist architectural traditions on the 20th century. Germany was one of the cradles of the modern movement and functionalism in architecture in the early 20th century and this approach is still strongly represented in the region today. This shows that sustainability aesthetics cannot considered as universal and cultural. Regional characteristics and the spirit of a particular place play an important role. 
To conclude, it can be asked what messages are encoded in the architectural expression of the analyzed certified sustainable buildings. According to the analysis of the literature, these messages range from exposing ecological crises, to demonstrating interest in ecology, to creating highly attractive objects and environments, intended to promote ecologically oriented attitudes and behaviors. The analyzed examples do not correspond to any of these trends. The exception is the examples of wooden architecture, which convey the message of comfortable and healthy living. The majority of the analyzed examples actually communicate the message that the visual status quo of the built environment can be maintained with less environmental impact. This situation is actually far from the change in aesthetic language of architecture predicted by Heymann [18].

Author Contributions: A.D.- data collection and analysis, writing an article, text edition for the final version; I.G.-V.-concept of the research, drafting literature review, critical revision of the article, supervisions. All authors have read and agreed to the published version of the manuscript.

Funding: The Baltic University Programme.

Institutional Review Board Statement: Not applicable.

Informed Consent Statement: Not applicable.

Data Availability Statement: Not applicable.

Conflicts of Interest: The authors declare no conflict of interest.

\section{References}

1. Lozano, R. Envisioning sustainability three-dimensionally. J. Clean. Prod. 2008, 16, 1838-1846. [CrossRef]

2. Throsby, D. Economic and Culture; Cambridge University Press: Cambridge, UK, 2001.

3. Brennan, A.; Lo, Y.S. Environmental Ethics. Stanford Encyclopedia of Philosophy, 2015. Available online: https://plato.stanford. edu/entries/ethics-environmental/ (accessed on 3 September 2020).

4. Grant, L.K. Sustainability: From excess to aesthetics. Behav. Soc. Issues 2010, 19, 7-47. [CrossRef]

5. Hill, G. The Aesthetics of Architectural Consumption. In Aesthetics of Sustainable Architecture; Lee, S., Ed.; 010 Publishers: Rotterdam, The Netherlands, 2011; pp. 26-40.

6. Kagan, S. Aesthetics of sustainability: A transdisciplinary sensibility for transformative practices. Transdiscipl. J. Eng. Sci. 2011, 2, 65-73. [CrossRef] [PubMed]

7. Level(s). The European Framework for Sustainable Buildings. 2021. Available online: https://ec.europa.eu/environment/topics/ circular-economy/levels_en (accessed on 10 November 2020).

8. Fox, W. Introduction. In Ethics and the Built Environment; Fox, W., Ed.; Routledge: London, UK, 2000.

9. Lee, S. Aesthetics of Sustainable Architecture; 010 Publishers: Rotterdam, The Netherlands, 2011.

10. Jauslin, D. Landscape aesthetics for sustainable architecture. In Aesthetics of Sustainable Architecture; Lee, S., Ed.; 010 Publishers: Rotterdam, The Netherlands, 2011; pp. 109-119.

11. United Nations. Sustainable Development Goals. Available online: https://www.un.org/sustainabledevelopment/sustainabledevelopment-goals / (accessed on 16 October 2020).

12. Transforming Our World: The 2030 Agenda for Sustainable Development. 2015. Available online: https://sdgs.un.org/2030 agenda (accessed on 20 October 2020).

13. Stelbiene, A. Architectural Quality Criteria. A Collection of Scientific Articles. Architecture Objects and Contexts 1; VGTU leidykla Technika: Vilnius, Lithuania, 2015; pp. 28-39. ISSN 2424-3884. eISSN 2424-3892; Available online: http://dspace.vgtu.lt/ bitstream/1/1881/3/2330-M_Architekturos_kriterijai_.pdf (accessed on 12 October 2020).

14. Energy Performance Certificates. European Commission, 2021. Available online: https://ec.europa.eu/energy/eu-buildingsfactsheets-topics-tree/energy-performance-certificates_en (accessed on 5 September 2020).

15. Lithuanian Law of Architecture. Vilnius. 2017. Available online: https://e-seimas.lrs.lt/portal/legalAct/lt/TAD/3658622050c9 11e78869ae36ddd5784f?jfwid=-g0zrz4bb7 (accessed on 3 March 2020).

16. Moldavanova, A. Sustainability, aesthetics, and future generations: Towards a dimensional model of the arts' impact on sustainability. In Transitions to Sustainability: Theoretical Debates for a Changing Planet; Humphreys, D., Stober, S.S., Eds.; Common Ground Publishing: Campaign, IL, USA, 2004; pp. 172-193.

17. Brown, M.; Haselsteiner, E.; Apró, D.; Kopeva, D.; Luca, E.; Pulkkinen, K.; Vula Rizvanolli, B. (Eds.) Sustainability, Restorative to Regenerative; COST Action CA16114 RESTORE, Working Group One Report: Restorative Sustainability; Urbanity-Architecture, Art, Culture and Communication: Viena, Austria, 2018.

18. Heymann, D. An Un-Flushable Urinal, Places Journal. June 2012. Available online: https:/ / placesjournal.org/article/an-unflushable-urinal-the-aesthetic-potential-of-sustainability / (accessed on 3 March 2020). 
19. Brook, I. Can 'Spirit of Place' be a Guide to Ethical Building? In Ethics and the Built Environment; Fox, W., Ed.; Routledge: London, UK, 2000.

20. Berardi, U. Sustainability assessment in the construction sector: Rating sys-tems and rated buildings. Sustain. Dev. 2012, 20, 411-424. [CrossRef]

21. Kamičaitytè-Virbašienè, J.; Gražulevičiūtè-Vileniškè, I. Darnios architektūros genotipas ir fenotipas. Town Plan. Archit. 2011, 35, 82-91. [CrossRef]

22. Marchand, A.; Walker, S.; De Coninck, P. The role of beauty for sustainability: A discussion on responsible consumption, aesthetics attitudes and product design. WIT Trans. Ecol. Environ. 2006, 99, 371-380.

23. Musacchio, L.R. The scientific basis for the design of landscape sustainability: A conceptual framework for translational landscape research and practice of designed landscapes and the six Es of landscape sustainability. Landsc. Ecol. 2009, 24, 993-1013. [CrossRef]

24. Di Carlo, I. The AESTHETICS of Sustainability. Systemic Thinking and Self Organization in the Evolution of Cities. ListLaboratorio Internazionale Editoriale Sas, 2016. Available online: https:/ / www.academia.edu/22793307/The_aesthetics_of_ sustainability_systemic_thinking_in_the_evolution_of_cities (accessed on 12 October 2020).

25. Guy, S.; Farmer, G. Reinterpreting sustainable architecture: The place of technology. J. Archit. Educ. 2001, 54, 140-147. [CrossRef]

26. Sauerbruch, M.; Hutton, L. What does sustainability look like? In Aesthetics of Sustainable Architecture; Lee, S., Ed.; 010 Publishers: Rotterdam, The Netherlands, 2011; pp. 41-49.

27. Wang, P.-C.; Yu, C.-Y. Aesthetic experience as an essential factor to trigger positive environmental consciousness. Sustainability 2018, 10, 1098. [CrossRef]

28. Kamicaityte-Virbasiene, J.; Grazuleviciute-Vileniske, I. Premises for development of sustainable architecture in urban environment. Town Plan. Archit. 2009, 33, 363.

29. IB, Conseil International du Bâtiment. Towards Sustainable and Smart-Eco Buildings. Summary Report on the EU-Funded Project Smart-ECO Buildings in the EU, Rotterdam, CIB. 2010. Available online: https:/ / www.irbnet.de/daten/iconda/CIB18098.pdf (accessed on 9 October 2020).

30. Sunikka-Blank, M. The concept and aesthetics of sustainable building in Japan. In Aesthetics of Sustainable Architecture; Lee, S., Ed.; 010 Publishers: Rotterdam, The Netherlands, 2011; pp. 186-197.

31. Knowles, R.L. Solar aesthetic. In Aesthetics of Sustainable Architecture; Lee, S., Ed.; 010 Publishers: Rotterdam, The Netherlands, 2011; pp. 50-65.

32. Bothwell, K. The architecture of the passively tempered environment. In Aesthetics of Sustainable Architecture; Lee, S., Ed.; 010 Publishers: Rotterdam, The Netherlands, 2011; pp. 66-78.

33. Finocchicaro, L.; Hestnes, A.G. Symbiosis and Mimesis in the Built Environment. In Aesthetics of Sustainable Architecture; Lee, S., Ed.; 010 Publishers: Rotterdam, The Netherlands, 2011; pp. 259-271.

34. Meyer, E.K. Sustaining beauty: The performance of appearance: A manifesto in three parts. J. Lands. Archit. 2008, 3, 6-23. [CrossRef]

35. Attfield, R. Environmental Philosophy and Environmental Ethics for Sustainability; Oxford University Press: Oxford, UK, 2018.

36. Istiadji, A.D.; Hardiman, G.; Satwiko, P. What is the sustainable method enough for our built environment? IOP Conf. Ser. Earth Environ. Sci. 2018, 213, 012016. [CrossRef]

37. Delancey, C. Architecture Can Save the World: Building and Environmental Ethics. Philos. Forum. 2004, 35, 147-159. [CrossRef]

38. International Living Building Institute. Living Building Challenge 4.0.; International Living Building Institute: Seattle, WA, USA, 2019; pp. 64-65. Available online: https:/ /living-future.org/wp-content/uploads/2019/04/Living-Building-Challenge-4.0.pdf (accessed on 11 November 2020).

39. DGNB. Overview of the Criteria. Available online: www.dgnb-system.de/en/buildings/new-construction/criteria/ (accessed on 12 October 2020).

40. BREEAM. (n.d.) Case Studies. Available online: https://www.breeam.com/case-studies/ (accessed on 5 September 2020).

41. Vierra, S. Green Building Standards and Certification Systems. WBDG. 8 May 2019. Available online: www.wbdg.org/resources/ green-building-standards-and-certification-systems (accessed on 5 September 2020).

42. Souza, E. Evaluating Buildings: 12 Green Building Certifications to Know. ArchDaily. 27 August 2020. Available online: https: / / www.archdaily.com/946290/evaluating-buildings-12-green-building-certifications-to-know $\backslash \mathrm{T} 1 \backslash$ textgreater \{\} (accessed on 15 November 2020).

43. USGBC. Projects. Available online: https://www.usgbc.org/projects (accessed on 14 October 2020).

44. DGNB System. Projects. Available online: https://www.dgnb-system.de/en/projects/ (accessed on 15 October 2020).

45. Pintos, P.; Powerhouse Brattørkaia/Snøhetta. Archdaily. 2019. Available online: https://www.archdaily.com/924325 /powerhouse-brattorkaia-snohetta (accessed on 8 September 2020). 